\title{
La conservación al servicio del desarrollo sostenible de todos los tipos de bosques del mundo: Compendio de conceptos y términos ${ }^{1}$
}

\author{
Recopilación realizada por Paul L. Aird ${ }^{2}$
}

La conservación de los bosques ha surgido como un tema prioritario en los programas internacionales de los sectores político, científico, ambiental y comercial. Durante y después de la Conferencia de las Naciones Unidas sobre Ambiente y Desarrollo Sostenible llevada a cabo durante la Cumbre Mundial celebrada en Río de Janeiro en junio de 1992, el tema de los bosques del mundo surgió en numerosos foros, deliberaciones y negociaciones internacionales. La comprensión e interpretación de los términos ligados al bosque y a la dasonomía constituyen un elemento fundamental para mantener, a nivel internacional, un diálogo constructivo y eficaz acerca de la temática forestal.

Los términos listados en este compendio se emplean corrientemente en conversaciones y escritos de orden científico, técnico o general, relativos a la conservación para el desarrollo sostenible de todos los tipos de bosques del mundo. Los términos son presentados aquí con sus definiciones y explicaciones para propiciar un consenso nacional e internacional en su entendimiento.

\footnotetext{
${ }^{1} \mathrm{El}$ autor desea expresar su agradecimiento por la valiosa contribución de los siguientes miembros del Canadian Forest Service, del Natural Resources Canada: al Dr. J.S. Maini, quien propuso y dio su apoyo a este trabajo; al Dr. T. Boyle y al Dr. O. Hendrickson, por sus valiosas sugerencias, así como al $\mathrm{Sr}$. N. Lafrenière y al Dr. M. Boudoux, quienes coordinaron la traducción del manuscrito; al Sr. François Lavallée y a la Sra. Francine Bertrand por las traducciones al francés y al español respectivamente. También se agradece al Sr. Marc Sabourin, del Pest Diagnostic Clinic, Ontario Ministry of Agriculture, Food and Rural Affairs, y a la Dra. M. Isabel Bellocq, de la Faculty of Forestry, University of Toronto por la revisión de las versiones francesa y española, respectivamente; y a varios estudiantes revisores.

${ }^{2}$ Profesor, Forest Conservation and Policy, Faculty of Forestry, University of Toronto, Toronto (Ontario), Canadá M5S 3B3
}

Las palabras tienen a menudo diferentes interpretaciones, lo cual puede dar lugar a usos erróneos. Se espera que esta lista de términos especializados fomente el desarrollo, utilización y comprensión de una terminología uniforme, evitando al mismo tiempo el empleo de términos ambiguos.

En el caso de algunos términos, como lluvia ácida, abundan las definiciones. Las hemos estudiado minuciosamente antes de elegirlas y adaptarlas, para presentar lo que parece ser la definición más apropiada y detallada para un uso uniforme. En algunos casos, el lector encontrará precisiones adicionales, así como nuevas definiciones.

No se ha recurrido a las definiciones de los diccionarios usuales, a veces por su carácter anticuado, con frecuencia porque no conciernen específicamente a la conservación del bosque y, en otros casos, por respeto al derecho de autor. Por lo tanto, la recopilación de este glosario especializado exigió una amplia consulta literaria.

En algunos casos, las definiciones pertenecen al autor. En caso contrario, cada definición va acompañada de su respectiva fuente original, la cual figura en la lista de referencias.

Nótese que muchas de las definiciones y explicaciones presentadas no constituyen citas exactas. El trabajo consistió, principalmente, en seleccionar los términos ligados a la conservación del bosque y copiar, revisar, transcribir o redactar las definiciones para clarificar su sentido y uso en la colectividad internacional.

Los comentarios y sugerencias destinadas a mejorar esta recopilación, tanto bajo forma de añadidos como de supresiones o revisiones, serán bien acogidas. El resultado final podría ser llegar a un consenso universal acerca de la terminología a utilizar en materia de conservación del bosque.

\section{Conceptos y términos en conservación de bosques (Referencias en inglés y francés respectivamente)}

abiótico (abiotic, abiotique) caracterizado por la ausencia de vida; referente a los elementos inanimados del medio ambiente

acumulación biológica (bioacumulación) (biological accumulation (bioaccumulation), accumulation biologique (bioaccumulation)) denominada también "amplificación biológica". Aumento gradual de la concentración de una substancia persistente en un organismo a medida que éste envejece, o en una serie de organismos, desde los productores primarios hasta los consumidores primarios y secundarios

administración (stewardship, intendance) la ciencia, arte y habilidad de manejar los recursos responsable y controladamente

administrador (steward, intendant) persona encargada de la supervisión y manejo de los recursos agotamiento (depletion, épuisement) reducción gradual o destrucción de recursos naturales o de fuentes de energía, dinero, productos, etc.

agrosilvicultura (agroforestry, agroforesterie) término general que designa los regímenes de manejo consistentes en integrar deliberadamente plantas leñosas perennes al cultivo, a la cría de ganado o a ambas cosas, sobre la misma unidad de manejo de la tierra. La integración puede tomar la forma de una coexistencia espacial o de una alternancia temporal. En agrosilvicultura, suelen existir interacciones ecológicas y económicas entre los elementos leñosos y no leñosos (Consejo Internacional para Investigación en Agrosilvicultura 1991)

aldea global (global village, village planétaire) la nueva 
interdependencia electrónica crea de nuevo el mundo a imagen de una aldea planetaria. Con la transmisión eléctrica de la información a la velocidad de la luz, todos los acontecimientos del planeta suceden simultáneamente, sin separación en el tiempo y el espacio. En lo sucesivo, se puede vivir no sólo en una región o un país: se puede vivir simultáneamente en varias culturas y en varios mundos (McLuhan 1967; McLuhan y Forsdale 1988)

análisis de vulnerabilidad (de viabilidad) de una población (population vulnerability (viabiliy) analysis, analyse de vulnérabilité (de viabilité) d'une population) técnica analítica que estima el tamaño mínimo de una población viable necesario para que la especie asegure su existencia (Gilpin y Soulé 1986)

árbol (tree, arbre) planta leñosa perenne que consta de un tronco, o fuste, que sostiene una copa de ramas y hojas; abarca también los grandes arbustos, los bambúes, las cañas, etc. (Society of American Foresters 1971, 1983)

banco de genes (gene bank, banque de gènes) facilidad establecida para la conservación $e x$-situ de tejidos reproductivos o células de organismos, tal como un banco de semilla o un banco de esperma (World Resources Institute y otros 1992)

biología de la conservación (conservation biology, biologie de la conservation) disciplina que trata acerca de la biodiversidad, los procesos naturales que la producen, y las técnicas usadas para mantenerla frente a los disturbios ambientales causados por el ser humano (Wilson 1992)

bioenergía (bio-energy, bioénergie) energía cinética liberada por la biomasa consumida, quemada o convertida en combustible, o energía potencial contenida en la misma biomasa (Commission of the European Communities 1983; Hendrickson 1993)

bioma (biome, biome) conjunto vasto y complejo de organismos que comparten el mismo entorno (ejemplo: el bosque boreal de coníferas) condicionado por el clima y el suelo (Tansley 1935)

biomasa (biomass, biomasse) peso (o estimación equivalente) de la materia orgánica, incluyendo los animales, las plantas y los microorganismos, vivos o muertos, por encima y por debajo de la superficie del suelo (Aird 1979)

biosfera (biosphere, biosphère) parte de la tierra y la atmósfera donde pueden subsistir organismos vivos (Australia, Resource Assessment Commission 1991)

biota (biota, biote) conjunto de organismos que se encuentran en un área determinada (Keystone Center 1991)

biótico (biotic, biotique) que es propio de la vida; relativo al elemento animado del ambiente

bosque (forest, forêt) ecosistema compuesto predominantemente por árboles y otra vegetación leñosa que crecen juntos de manera más o menos densa (Society of American Foresters 1971, 1983).

Paisaje dominado por árboles y otra vegetación leñosa, y cuya cubierta representa por lo menos el 20\% de la superficie total (Maini 1991). Comprende las siguientes categorías:

bosque de producción (production forest, forêt de production) bosque manejado para obtener productos forestales pero preservando la bioproductividad del sistema. La diversidad bióti- ca o abiótica del bosque puede alterarse con la roturación, la plantación o el cultivo de especies seleccionadas, incluida la introducción de variedades exóticas o de crecimiento rápido

bosque natural (natural forest, forêt naturelle) bosque que ha evolucionado y se ha renovado naturalmente a partir de organismos que ya estaban en el lugar y sobre el cual la actividad humana no produjo alteraciones significativas. Un bosque natural no es equivalente de un "rodal clímax", aunque pueda incluirlo

bosque patrimonial (heritage forest, forêt patrimoniale) bosque manejado para obtener productos forestales y para conservar el sistema natural, incluyendo su bioproductividad y su diversidad biótica y abiótica. Se pueden usar técnicas, equipamientos y métodos modernos para la cosecha y cuidados silvícolas, enfatizando la reforestación natural conjuntamente con la implantación artificial de especies endémicas apropiadas

bosque permanente (permanent forest, forêt permanente) bosque que ha sido designado, en virtud de una política de usos de la tierra, para mantener permanentemente su cubierta, y que no sirva para otro fin (Maini y Ulsten 1991)

bosque rural (farm forest/rural forest, forêt rurale) arboles, setos, cortavientos, semilleros, plantaciones, bosques y organismos asociados, localizados en terrenos agrícolas o pastizales

bosque tampón (buffer forest, forêt tampon) bosque que separa y sirve de zona de transición entre dos áreas manejadas con fines diferentes: por ejemplo, bosque que separa un parque nacional de un área de cultivo, manejada de forma tal que pueda tanto proteger el valor del parque como proporcionar los productos forestales necesarios para la comunidad rural

bosque tradicional (traditional forest, forêt traditionnelle) bosque que se reproduce natural y continuamente gracias a los organismos ya establecidos en él y que se explota por los métodos tradicionales, conforme a los usos y costumbres que se perpetúan desde hace muchos años, para responder a las necesidades locales

bosque urbano (urban forest, forêt urbaine) arboles, bosques y organismos asociados que crecen cerca de edificios y en jardines, zonas verdes, parques y campos de golf, situados en un pueblo, una ciudad, en áreas urbanas y suburbanas

rodal maduro (old-growth forest, forêt ancienne) masa forestal dominada por organismos maduros, originados naturalmente a partir de organismos endémicos del bosque o de sus alrededores, y sobre la cual la actividad humana no produjo cambios significativos en la genética y diversidad de especies y estructuras

brinzal (sapling, gaule) término general para designar un árbol joven, que no es un plantín pero tampoco un árbol adulto, es decir que mide aproximadamente más de un metro de altura y de 1,5 a $10 \mathrm{~cm}$ de diámetro (Society of American Foresters, 1971, 1983)

canon (stumpage, droits de coupe) precio exigido como com- 
pensación del derecho de cosechar madera en un terreno forestal público o privado

capacidad de alojamiento (carrying capacity 3, capacité récréative) ver "carga" y "carga cinegética". Número máximo de usuarios que puede soportar una zona recreativa sin producir un deterioro en la calidad de las actividades recreativas ni de los recursos (Society of American Foresters 1971,1977, 1983; Republic of the Philippines 1982)

capacidad de carga ver "carga cinergética"

carbono ver "depósito de carbono" y "pozo de carbono"

carga (carrying capacity 2, possibilité de charge) ver "capacidad de alojamiento" y "carga cinegética". Población máxima de ganado que puede soportar una extensión o un terreno dado ocupado por fauna silvestre, sin que disminuya ni la cantidad ni la calidad de sus pastizales ni tampoco el valor de los demás recursos ligados al mismo terreno, incluyendo el suelo, la vegetación y la cuenca (Society of American Foresters, 1971, 1977, 1983; Republic of the Philippines 1982)

carga cinergética (capacidad de carga) (carrying capacity 1 , capacité de charge) véase también "capacidad de alojamiento" y "carga". Número (o peso) de los organismos de una especie y una calidad dadas, que pueden sobrevivir en un determinado ecosistema sin causar deterioro en éste, en las condiciones más desfavorables del medio que se puedan producir en un intervalo dado (Society of American Foresters 1971, 1977, 1983; Republic of the Philippines 1982)

clon (clone, clone) individuo o grupo de individuos nacidos por reproducción asexual y, por lo tanto, genéticamente idénticos a su progenitor

comerciable (merchantable, marchand) se aplica a la parte de un árbol o una cosecha que puede ser comercializada en determinadas condiciones económicas (Empire Forestry Association 1953)

comunidad (community, communauté) grupo integrado por especies que habitan un área dada y que influyen mutuamente en su distribución, abundancia y evolución (World Resources Institute y otros 1992)

conservación (conservation, conservation) manejo humano de la biosfera, con el objeto de que las generaciones actuales obtengan los máximos beneficios sostenibles sin disminuir su capacidad de respuesta a las necesidades y aspiraciones de generaciones futuras, lo cual abarca la preservación, el mantenimiento, la utilización sostenible, el restablecimiento y el mejoramiento del medio ambiente. La teoría moderna de la conservación añade que los esfuerzos de conservación no contemplan tanto el estado físico de un sistema ecológico como los procesos ecológicos que dan lugar a este estado y lo mantienen (Australia, Resource Assessment Commission 1991). La conservación va dirigida tanto a los bosques destinados a la explotación como a las reservas ecológicas, aunque los objetivos del manejo difieran (Maini y Carlisle 1974)

contaminar (contaminate, contaminer) 1: volver algo impuro al ponerlo en contacto o mezclarlo con una substancia extraña o nociva; alterar, infectar, envenenar, ensuciar; 2: (pollute, polluer) alterar la tierra, el agua, el aire, la vegetación, los animales o los microorganismos con substancias consideradas nocivas para la salud de los organismos vivos

crecimiento sostenible (sustainable growth, croissance durable) "crecimiento sostenible" es un término contradictorio: nada físico puede crecer indefinidamente (World Conservation Union y otros 1991)

cubierta forestal (forest cover, couvert forestier) conjunto de árboles y otras plantas que ocupan el suelo de un bosque, incluida la vegetación herbácea (Society of American Foresters 1971, 1983)

cuenca hidrográfica (watershed, bassin hydrographique) área drenada por un río o una red hidrográfica subterránea o de superficie

cultura (culture, culture) conjunto de estilos de vida creados por un grupo humano y transmitidos de generación en generación (Australia, Resource Assessment Commission 1991)

dasonomía (forestry, foresterie) de manera general, profesión que abarca a la ciencia, la comercialización y el arte de crear, conservar y manejar bosques y terrenos forestales de forma que se posibilite una utilización permanente de sus recursos materiales y recreativos. Ciencia, arte y práctica del manejo y la utilización, para provecho del hombre, de los recursos naturales que se encuentran en las tierras forestales o que están asociados a ellas (Society of American Foresters 1971, 1983)

degradación (degradation, dégradation) disminución de la productividad o de la diversidad biológicas (Sargent y Lowcock 1991). Reducción del nivel, de la calidad, del rendimiento, etc.

depósito ácido (acidic deposition, dépôt acide) proceso por el cual los ácidos se incorporan a la lluvia, la nieve, etc. ("depósito húmedo") o por el cual las cenizas volantes, los sulfatos, los nitratos y los gases, como el anhídrido sulfuroso y el óxido de nitrógeno, son depositados o absorbidos en una superficie ("depósito seco"). Las partículas secas y los gases pueden transformarse en ácidos después de estar depositados o absorbidos si toman contacto con el agua (Canada, House of Commons 1981)

depósito de carbono (reservoir, carbon; réservoir à carbone) zona en la que se ha acumulado carbono en cantidad apreciable como consecuencia de la actividad, pasada o presente, de un pozo de carbono (Hendrickson 1993)

depresión por consanguinidad (inbreeding depression, dépression de consanguinité) disminución de la variabilidad genética debido al apareamiento de individuos emparentados en alto grado (Baker 1989)

deriva genética (genetic drift, dérive génétique) la muestra aleatoria de los genes transmitidos de una generación a la siguiente tiende a perder variación genética, llamada deriva genética, la cual ocurre con mayor rapidez en las poblaciones pequeñas que en las poblaciones numerosas (Lacy 1987)

desarrollo (development, développement) progreso del manejo y de la utilización de los recursos naturales, encaminado a satisfacer las necesidades de los seres humanos y a mejorar su calidad de vida. Para garantizar un desarrollo sostenible, hay que tener en cuenta los factores sociales, ecológicos y económicos de la base de los recursos vivientes y no vivientes, y las ventajas y desventajas a corto y largo plazo de acciones alterna- 
tivas (International Union for Conservation of Nature and Natural Resources 1980)

desarrollo forestal sostenible (sustainable forest development, développement durable des forêts) comprende el mantenimiento, sin una degradación inaceptable, del potencial de producción y de renovación, así como la diversidad genética, específica y ecológica de los ecosistemas forestales (Maini 1989)

desarrollo sostenible (sustainable development; développement durable, écodéveloppement) desarrollo que responde a las necesidades del presente sin comprometer la habilidad de las generaciones futuras para satisfacer las suyas. El desarrollo sostenible implica satisfacer las necesidades básicas de todos y proporcionar a cada uno la oportunidad de satisfacer sus aspiraciones para una vida mejor. Más que un estado de armonía inmutable, es un proceso de cambio en el cual la explotación de los recursos, la orientación de las inversiones, el sentido del desarrollo tecnológico y la evolución de las instituciones tienen en cuenta tanto las necesidades futuras como las presentes (World Commission on Environment and Development 1987). Ver "desarrollo sostenido"

desarrollo sostenido (sustained development, développement soutenu) desarrollo mantenido, con frecuencia de forma demasiado poco sensible a las limitaciones sociales o ecológicas. Ver "desarrollo sostenible"

desforestación (deforestation, déboisement) acción de eliminar el bosque de forma permanente para un uso no forestal. $\mathrm{Si}$ la cosecha (incluso con extracción del tocón) va seguida de una reforestación para fines forestales no se considera desforestación (Society of American Foresters 1971, 1983)

diversidad biológica (biodiversidad) (biological diversity (biodiversity), diversité biologique (biodiversité)) variedad y variabilidad observadas en los organismos vivos en todos los tipos de ecosistemas, terrestres, marinos o de agua dulce, así como entre los conjuntos ecológicos de los cuales son parte. Incluye la diversidad dentro de una especie, entre las especies o en un ecosistema (United Nations Environment Programme 1992)

diversidad ecosistémica (ecosystem diversity, diversité écosystémique) variedad y variabilidad de los hábitats, de las comunidades bióticas, de los elementos abióticos y de los procesos existentes en una región dada (McNeely y otros 1990)

diversidad específica (species diversity, diversité spécifique) expresión que hace referencia a la variedad de los organismos vivos sobre la tierra; se estima que el número de especies se sitúa entre 5 y 10 millones y más, aunque sólo 1,4 millón han sido descritas (McNeely y otros 1990). La diversidad específica toma en cuenta el número de especies y de poblaciones, así como su reparto dentro de una determinada área. Se la puede considerar en tres niveles: diversidad microcósmica (tipo alfa), que tiene en cuenta un mismo hábitat, diversidad intercósmica (tipo beta), que tiene en cuenta los cambios entre habitats a través de gradientes topográficos y climáticos, y diversidad macrocósmica (tipo gama), que se refiere a una gran superficie que abarca numerosos hábitats (Cody 1986, Tho 1991). Ver "riqueza específica" y "diversidad taxonómica" diversidad genética (genetic diversity, diversité génétique) variación de la composición genética de los individuos dentro de una especie, una variedad, una raza, o entre varias especies, variedades o razas; variación genética transmisible en una población o entre poblaciones (World Resources Institute y otros 1992)

diversidad cultural (cultural diversity, diversité culturelle) Variedad y variabilidad de las estructuras sociales, los sistemas de pensamiento y las estrategias de adaptación a las situaciones y a los cambios de orden biológico en las diferentes partes del mundo (World Resources Institute y otros 1992)

diversidad ecosistémica ver "diversidad biológica"

diversidad específica ver "diversidad biológica"

diversidad genética ver "diversidad biológica"

diversidad taxonómica (taxonomic diversity, diversité taxonomique) medida de la diversidad específica que tiene en cuenta el grado de parentesco. Por ejemplo, la tierra posee muchas más especies que el mar, pero las especies terrestres están emparentadas en un grado mucho más elevado que las especies oceánicas. Así pues, la diversidad de los ecosistemas marinos es mayor de lo que podría surgir por la simple enumeración de las especies (World Resources Institute y otros 1991)

domesticar (domesticate, domestiquer) ocuparse de un organismo silvestre o cultivarlo para satisfacer las necesidades del ser humano

ecología (ecology, écologie) rama de la ciencia que estudia las relaciones de los organismos vivos entre sí y con su medio ambiente (McNeely y otros 1990)

ecología forestal (silvics, écologie forestière) estudio de la historia de vida, los requerimientos y las características generales de los árboles y las masas forestales con relación al medio ambiente y a la práctica de la silvicultura (Society of American Foresters 1989)

ecosistema (ecosystem, écosystème) en un principio, según A.G. Tansley (1935), todo conjunto de organismos vivos en su medio, que "aislamos mentalmente con el fin de estudiarlo". El término abarca todos los organismos de una comunidad, así como el medio físico en el que se encuentran (Society of American Foresters 1971, 1983; Keystone Center 1991)

ecosistema forestal (forest ecosystem, écosystème forestier) sistema ecológico compuesto de elementos bióticos y abióticos del medio ambiente que se influencian mutuamente y donde la cubierta arbórea representa más del $20 \%$ de la superficie total (Maini 1991)

endémico ver "especie"

equilibrio ecológico (ecological balance, équilibre écologique) situación dinámica característica de una comunidad de organismos cuya diversidad genética, específica y ecosistémica permanece relativamente estable y sujeta a cambios graduales por sucesión natural

especie (species, espèce) población o serie de poblaciones de organismos que pueden aparearse entre sí pero no con miembros de otras especies (Keystone Center 1991) 
especie endémica (especie indígena) (endemic species (indigenous species), espèce endémique (espèce indigène)) especie originaria de una región particular o perteneciente a ella. Los adjetivos "endémica" e "indígena" se usan preferentemente a "autóctona"

especie exótica (exotic species, espèce exotique) especie introducida de manera fortuita o intencional en una región exterior a su área natural de distribución. Se prefiere el adjetivo "exótica" o "ajena" a "no autóctona"

especie indicadora (indicator species, espèce indicatrice) especie vegetal, animal o microbiana que presenta rasgos o reacciones características de un lugar, un hábitat, un ecosistema o una condición ambiental

espiral de extinción (extinction vortex, spirale d'extinction) procesos genéticos y demográficos que se manifiestan cuando una población se hace poco numerosa y aislada y sus representantes empiezan a reaccionar entre sí, de tal forma que se crea lo que se denomina "espiral de extinción". La erosión genética debida a la endogamia y las dificultades de adaptación pueden disminuir aún más una población ya reducida, lo cual hace cada vez más inseguras las posibilidades de reproducción, acentúa la despoblación, aumenta el grado de consanguinidad y empobrece la diversidad genética. Así la población se dirige ineluctablemente hacia la extinción a un ritmo cada vez más acelerado (Gilpin y Soulé 1986; Lacy y otros 1992)

estrategia mundial de conservación (world conservation strategy, stratégie mondiale de conservation) conjunto de estrategias internacionales, nacionales y regionales concebidas para alcanzar los tres grandes objetivos de conservación de los recursos vivientes (International Union for Conservation of Nature and Natural Resources 1980):

mantener los procesos ecológicos esenciales y los sistemas que sustentan la vida (regeneración y protección del suelo, reciclado de nutrientes, depuración natural de aguas), de los que dependen la supervivencia y el desarrollo de la humanidad;

preservar la diversidad genética (gama de material genético existente en los organismos del mundo), de la que dependen el funcionamiento de muchos de los procesos y sistemas mencionados anteriormente, los programas de selección necesarios para la protección y el mejoramiento de las plantas cultivadas, animales domésticos y microorganismos, así como una buena parte de los progresos científicos y médicos, las innovaciones técnicas y el futuro de numerosas industrias que utilizan recursos vivientes;

velar por la utilización duradera de especies y ecosistemas (en particular, los peces y otras especies silvestres, los bosques y los pastizales), de los que son tributarias millones de comunidades rurales y grandes industrias

explosión ecológica (ecoexplosión) (ecological explosion (ecoexplosion), explosion écologique (écoexplosion)) aumento extraordinario de los números de un organismo vivo; por ejemplo, multiplicación de un virus infeccioso como el de la gripe, de una bacteria como la de la peste bubónica, de un hongo como el de la enfermedad de la papa, de una planta verde como la chumbera, o un animal como la ardilla gris extinción (extinction, extinction) Desaparición de una especie causada por la ausencia de reproducción o por la muerte de todos sus representantes (McNeely y otros 1990)

extinguido (extinct, disparu) que ya no existe (Keystone Center 1991)

extirpación (extirpation, extirpation) extinción local; para una especie o una subespecie, hecho de desaparecer de un lugar o una región, pero sin llegar a extinguirse en toda el área de distribución (McNeely y otros 1990)

flora y fauna silvestres (wildlife, flore et faune sauvages) conjunto de mamíferos, aves, reptiles, anfibios, peces, invertebrados, plantas, hongos, algas, bacterias y otros organismos que viven en la naturaleza (Ontario Wildlife Working Group 1991). Organismos no humanos, no domesticados y no cultivados.

forestación (afforestation, boisement) acción de cubrir de árboles, por siembra, plantación o regeneración natural, un área en la que los árboles estuvieron ausentes desde siempre o desde largo tiempo (Society of American Foresters 1971, 1983).

gen (gene, gène) unidad funcional de la herencia; parte de la molécula de ácido desoxirribonucleico (ADN) que codifica una enzima única o una unidad proteica estructural única (World Resources Institute y otros 1992)

granja global ( global farm, ferme planétaire) noción nacida de la de la aldea global, con el fin de recalcar la interdependencia de las gentes, las naciones y la naturaleza. Gracias a la velocidad de los intercambios de información, hoy en día se puede ordenar, utilizar y compartir nuestro patrimonio biológico. La responsabilidad común de preservar la diversidad y la productividad biológicas del mundo, con el fin de eliminar, para todas las especies, las injusticias que pueda sufrir una generación con respecto a otras, remodela el mundo a imagen de una granja familiar planetaria. El jardín global y el bosque global son parte integrante de la granja global (Aird 1989)

habitantes del bosque (forest dwellers, habitants des forêts) personas que viven en un ecosistema forestal y tienen necesidad de él para conservar su modo de vida, sus estructuras sociales, su identidad cultural y sus conocimientos tradicionales, que se han de salvaguardar y respetar (Maini 1991). El término puede abarcar también a las "personas y otros organismos" como habitantes del bosque

hábitat (habitat, habitat) medio natural donde vive un organismo o una población. El término puede designar todos los organismos y su medio físico en un lugar particular (Canada Department of Agriculture 1976; Keystone Center 1991)

industria extractiva (resource industry, industrie extractive) industria basada en los recursos primarios sacados de la agricultura, la pesca y la explotación forestal y minera, como, por ejemplo, el trigo, el bacalao, la madera de pino o el mineral de hierro

integridad ecológica (de un ecosistema) (ecological (ecosystem) integrity, intégrité écologique (d'un écosystème)) cualidad de un ecosistema natural, con o sin manejo, donde tienen lugar procesos ecológicos naturales y donde la diversidad genética, específica y ecosistémica está asegurada para el futuro (Canadian Parks Service 1991) 
lluvia ácida (acid rain, pluie acide) lluvia cuyo $\mathrm{pH}$ es inferior a 5,6 (Cámara de los Comunes de Canadá, 1981). Se utiliza frecuentemente como sinónimo de depósito ácido o de precipitación ácida, lo cual, stricto sensu, es una equivalencia errónea

manejo con rendimiento sostenido (sustained-yield management, aménagement à rendement soutenu) ordenación forestal destinada a alcanzar lo antes posible un equilibrio entre el crecimiento y la cosecha (Society of American Foresters 1971, 1983)

manejo de la fauna silvestre (wildlife management, aménagement de la faune) aplicación de principios científicos y técnicos de mantenimiento de poblaciones y hábitats de especies silvestres (en particular, mamíferos, aves y peces), con fines esencialmente recreativos o científicos. Este término abarca la noción más restringida de la gestión de la caza e incluye objetivos semicomerciales, es decir, la limitación de piezas abatidas (Society of American Foresters 1971, 1983)

manejo del ecosistema (ecosystem management, aménagement de l'écosystème) conjunto de medidas tomadas por el ser humano, consistentes en seleccionar, planificar, organizar e implementar programas concebidos para alcanzar objetivos determinados a escala del ecosistema; puede tratarse de medidas de protección encaminadas a que la influencia humana no altere la naturaleza, o incluso de intervenciones más activas necesarias para mantener la diversidad, colocar instalaciones, controlar poblaciones o eliminar especies exóticas (McNeely y otros 1990)

manejo forestal (forest management, aménagement forestier) de manera general, aplicación de los principios científicos, económicos y sociales a la administración y a la explotación de un bosque para fines determinados; de forma más particular, rama del sector forestal que se ocupa de las cuestiones administrativas, económicas, jurídicas y sociales globales, así como por las actividades esencialmente científicas y técnicas, especialmente la silvicultura, la protección y la reglamentación del bosque (Society of American Foresters 1971, 1983)

manejo forestal sostenible (sustainable forest management, aménagement forestier durable) régimen de ordenación de un territorio forestal encaminado a mantener las capacidades de producción y de renovación, así como la diversidad genética, específica y ecológica de los ecosistemas forestales. El manejo forestal sostenible es necesario para el desarrollo forestal sostenible (Maini 1991)

manejo integrado de recursos (integrated resource management, aménagement intégré des ressources) manejo común de dos o más recursos naturales (agua, suelo, madera, pastos, fauna, recreación, etc.) en el que se integran los valores y los intereses de la comunidad planetaria en la concepción, la planificación y la implementación de políticas, programas y proyectos encaminados a utilizar y preservar estos recursos a perpetuidad (Mitchell 1986; Peel 1991)

manejo sostenible (sustainable management, aménagement durable) gestión de la utilización, la explotación y la protección de recursos naturales y físicos de una forma y a un ritmo que permitan a las personas o colectividades asegurar su bienestar social, económico y cultural, así como preservar su salud y su seguridad, a) conservando el potencial de los recursos naturales y físicos (a excepción de los minerales) para responder a las necesidades razonables previsibles de las generaciones futuras, b) salvaguardando la aptitud del aire, del agua, del suelo y de los ecosistemas para mantener la vida y, c) evitando, corrigiendo $\mathrm{o}$ atenuando los efectos nocivos de las actividades sobre el medio ambiente (New Zealand Government 1991)

mantener (sustain, maintenir) satisfacer en permanencia las necesidades de la vida; permanecer vivo; preservar la calidad, la cantidad, la productividad, la biodiversidad

medio ambiente (environment, environnement) conjunto de los elementos bióticos y abióticos de un lugar que influyen sobre el desarrollo de la vida (Empire Forestry Association 1953)

mejora de los árboles (tree improvement, amélioration des arbres) término mal elegido que designa la selección, la evaluación y la mejora genética de los árboles con el objeto de conferirles las características deseadas, tales como un rápido crecimiento y una resistencia a la sequía, a las enfermedades y a las plagas

monocultivo (monoculture, monoculture) selección y cultivo, por siembra, plantación o mejora, de una especie, una variedad, una cepa genética o un clon, acompañados con frecuencia de la destrucción o la exclusión de otros organismos

monumento natural, sitio natural ver "zona protegida"

nicho (niche, niche) entorno único que permite la existencia de un organismo o una especie

organismo (organism, organisme) todo ser viviente compuesto de una o varias células

paisajes terrestres y marinos protegidos ver "zona protegida" parque ver "zona protegida"

patrimonio (heritage, patrimoine) aquello que las personas o las colectividades pueden heredar y transmitir a sus sucesores

patrimonio cultural (cultural heritage, patrimoine culturel) Costumbres, tradiciones, literatura, arte, colecciones de museos, edificios históricos, senderos, rutas. (Ontario Ministry of Culture and Communications 1990)

patrimonio natural (natural heritage, patrimoine naturel) tierra, agua, aire, rocas, fósiles, plantas, hongos, animales, microorganismos, hábitats y ecosistemas

pesticida (pesticide, pesticide) producto natural o artificial usado para inhibir, suprimir o matar una peste que se considera nociva para el crecimiento, el desarrollo o la supervivencia de otros organismos; entre ellos se incluyen los acaricidas, arboricidas, biocidas, herbicidas, insecticidas, así como los productos aptos para la eliminación de polilla, nemátodos, peces, bacterias, hongos y virus

plantación (plantation, plantation) masa forestal con crecimiento controlado por el hombre, ya sea por siembra o por plantación (Society of American Foresters 1971, 1983)

pozo de carbono (sink, carbon; puits à carbone) zona donde la tasa de consumo de carbono por los organismos vivos excede la tasa de liberación, de manera que dicho elemento es activamente inmovilizado bajo formas orgánicas e inorgánicas (Hendrickson 1993)

precipitación ácida (acidic precipitation, précipitation acide) Lluvia, nieve o nieve fundente, granizo o bruma cuyo $\mathrm{pH}$, por 
lo general, es inferior a 5,6. (La escala de $\mathrm{pH}$ varía de cero, que representa la acidez máxima, a 14, que representa una acidez nula; un pH de 7 caracteriza una solución neutra. $\mathrm{El} \mathrm{pH}$ normal de la lluvia, 5,6, se acidifica debido a reacciones químicas con el dióxido de carbono en la atmósfera terrestre). Las precipitaciones ácidas son principalmente el resultado de la emisión gaseosa de óxidos de azufre y de nitrógeno que se transforman en ácidos sulfúrico y nítrico, respectivamente, durante el transporte atmosférico, que puede extenderse sobre cientos o miles de kilómetros (Canada, House of Commons 1981)

preservación (preservation, préservation) acción de reservar, proteger o salvaguardar una parte del medio natural contra un factor de perturbación que no es natural. La preservación no implica mantener una zona en su estado actual, porque los procesos naturales ecológicos continuarán. La preservación forma parte de la conservación y no se opone a ella

productividad biológica (bioproductividad) (biological productivity (bioproductivity), productivité biologique (bioproductivité)) capacidad de producir la biomasa; producción de biomasa

recurso (resource, ressource) todo lo que es útil, o puede llegar a serlo, para las personas u otros organismos: alimentos, combustible, bienes, bosques, minerales y dinero

recurso biológico (biological resource, ressource biologique) comprende los recursos genéticos, los organismos o parte de ellos, las poblaciones y cualquier otro elemento biótico de un ecosistema que presenta un valor real o potencial para la humanidad (United Nations Environment Programme 1992) o para otros organismos

recurso natural (natural resource; ressource naturelle, richesse naturelle) recurso renovable (bosque, agua, fauna, suelo, etc.) o no renovable (petróleo, carbón, mineral de hierro, etc.) que ofrece la naturaleza (McNeely y otros 1990). Ver "industria extractiva"

reforestación (reforestation, reboisement) acción de repoblar con árboles una tierra forestal (Society of American Foresters 1971, 1983)

reforestar (reforest, reboiser) cubrir de árboles un terreno forestal, viejo o reciente, por medios naturales o artificiales

regeneración artificial (artificial regeneration, régénération artificielle) renovación de una masa forestal por siembra directa, con plantones o esquejes (Society of American Foresters 1971, 1983)

regeneración natural (natural regeneration, régénération naturelle) renovación de una masa forestal con semillas naturales, retoños por la raíz o por acodadura (Society of American Foresters 1989)

rendimiento sostenido (sustained yield, rendement soutenu) producción que puede extraerse permanentemente de un cultivo o de una población, según una intensidad de manejo dada (Society of American Foresters 1971, 1983)

reserva ver "zona protegida"

reservorio de genes (gene pool, réservoir de gènes) todos los genes de una especie, subespecie o grupos de organismos que se reproducen entre si restauración (restoration, restauration) retorno de un ecosistema o de un hábitat a la estructura de comunidad original, a la complementaridad natural de sus especies y a sus funciones naturales (World Resources Institute y otros 1992)

riesgo de extinción (extinction risk, risque d'extinction) se puede difinir el riesgo de extinción prematura en términos de probabilidades de extinción en un período de tiempo dado. Estas probabilidades se fundan en la teoría del tiempo de extinción para una población particular y en los plazos significativos para los programas de conservación. Existen tres categorías basadas en la disminución de los riesgos de extinción y en el aumento de los plazos:

especie crítica el $50 \%$ de probabilidad de extinción en 5 años, o un máximo de dos generaciones

especie amenazada el $20 \%$ de probabilidad en 20 años, o un máximo de diez generaciones

especie vulnerable el $10 \%$ de probabilidad de extinción en 100 años (Mace y Lande 1991)

riqueza específica (species richness, richesse spécifique) número total de especies que se encuentran en un área dada, sin relación con el reparto (Tho 1991)

rodal (stand, peuplement) grupo continuo de plantas con la suficiente uniformidad, desde el punto de vista de la distribución de edad y tamaño, así como de la composición, estructura, calidad del sitio y/o del emplazamiento, para constituir una unidad distinta (Society of American Foresters 1989)

rodal maduro ver "bosque"

rotación (rotation, rotation) ciclo de regeneración, de desarrollo y de cosecha de una especie (ejemplo: pino gris) o de una gama de especies (ejemplo: maíz, avena, alfalfa); utilización en secuencia de diferentes partes de una zona (para caza, pastoreo, etc.)

silvicultura (silviculture, sylviculture) teoría y práctica cuyo objeto es regir el establecimiento, la composición, el crecimiento y la calidad de las masas forestales con vistas a alcanzar ciertos objetivos de manejo (Society of American Foresters 1989)

silvicultura y arboricultura urbana (urban forestry, foresterie urbaine) cultivo y manejo de árboles y bosques por su contribución actual y potencial al bienestar fisiológico, sociológico y económico de una sociedad urbana (Jorgensen 1986)

sucesión (succession, succession) evolución en el tiempo de la composición de especies en un ecosistema, con frecuencia según un orden previsible (Waring y Schlesinger 1985)

subespecie (subspecies, sous-espèce) subdivisión de una especie; población o conjunto de poblaciones que ocupan una zona precisa y difieren genéticamente de otras subespecies de la misma especie (World Resource Institute y otros 1992)

terreno forestal (forest land, terre forestière) superficie cubierta de masas forestales cultivadas o naturales destinadas a un uso forestal; comprende también los terrenos desprovistos de árboles pero que han de ser reforestados. Los prados y pastizales permanentes con árboles y arbustos dispersos no constituyen un terreno forestal (Maini 1991) 
uso múltiple (multiple use, usage polyvalent) dos o más actividades, tales como excursiones, caza, corta, realizadas en la misma zona ya sean a) mezcladas, b) en sectores separados $o, c)$ secuencialmente

utilización sostenible (sustainable use, utilisation durable) utilización de un organismo, de un ecosistema o de otros recursos renovables a una tasa que respete su potencial de renovación (World Conservation Union y otros 1991)

zona anegadiza (wetland, zone humide) zona cubierta de agua poco profunda durante ciertas estaciones o todo el año, o zona en la que el nivel del manto freático está próximo a la superficie, o incluso llega a aflorar. En ambos casos, la presencia de agua abundante ha causado la formación de suelos hidromorfos y ha fomentado el predominio de hidrofitas o de plantas hidrófilas (Ontario Ministry of Natural Resources and Ministry of Municipal Affairs 1991)

zona natural (wilderness, étendue naturelle) parte del paisaje natural suficientemente grande y variado como para constituir una unidad ecológica más o menos autorregulada, donde la interferencia del hombre con la tierra y las comunidades naturales de plantas y animales es mínima y donde la belleza y el carácter del paisaje confieren un valor estético, cultural y científico (Pimlott 1971)

zona protegida (protected area, zone protégée) área protegida por legislación, regulación o principios que tienden a limitar la presencia o la actividad del hombre (World Conservation Union 1991). La siguiente lista presenta ocho categorías de zonas protegidas y sus objetivos de manejo:

monumento natural, sitio natural (natural monument, natural landmark; monument naturel, repère naturel) para proteger y preservar lugares naturales por su valor peculiar o sus características únicas. Se trata de áreas relativamente reducidas señaladas con el fin de proteger una realidad precisa

paisajes terrestres y marinos protegidos (protected landscapes and seascapes, paysages terrestres et marins protégés) para conservar paisajes terrestres o marinos importantes que son característicos de la intervención armoniosa entre el ser humano, la tierra y el agua, permitiendo a la vez que el público disfrute de actividades recreativas y turísticas de forma integrada a la actividad económica y al modo de vida normales en la región. Se trata de paisajes terrestres o marinos naturales o culturales de gran belleza en los que se mantienen los usos tradicionales del suelo

parque nacional (national park, parc national) para proteger las zonas naturales, estéticas y dignas de interés nacional o internacional con fines científicos, educativos o recreativos. Se trata de áreas naturales relativamente grandes donde la actividad humana no ha tenido mayor influencia y donde está prohibido extraer cualquier materia con fines comerciales

reserva antropológica, zona biótica natural (anthropological reserve, natural biotic area; réserve anthropologique, zone biotique naturelle) para permitir que las sociedades que vivan en armonía con el medio ambiente conserven su modo de vida sin que lo altere la tecnología moderna. Esta categoría se utiliza cuando los pueblos indígenas explotan los recursos de una forma tradicional reserva de recursos (resource reserve, réserve de possibilité) para proteger los recursos naturales de la zona para su uso futuro e impedir o limitar las actividades de explotación que pudiesen alterar los recursos, antes de formular objetivos fundados en conocimientos y planificación apropiados. Se trata de una categoría "en compás de espera", utilizada hasta que sea posible una clasificación permanente

reserva natural integral (strict nature reserve, réserve naturelle intégrale) para proteger la naturaleza y mantener sin disturbios los procesos naturales, con objeto de poder disponer de ejemplos ecológicamente representativos del medio natural disponible para estudios científicos, monitoreo ambiental y educación, con el fin de mantener los recursos genéticos en un estado dinámico evolutivo

reserva natural manejada, reserva natural de fauna (managed nature reserve, wildlife sanctuary; réserve naturelle aménagée, réserve naturelle faunique) para asegurar las condiciones naturales necesarias con el fin de proteger especies, grupos de especies, comunidades bióticas o realidades físicas del medio ambiente que representan cierta importancia, cuando éstas necesitan la intervención del hombre para seguir existiendo. Se puede permitir la explotación controlada de ciertos recursos

zona de manejo integrado, zona de recursos manejados (multiple-use management area, managed resource area; zone d'aménagement intégré, zone de ressources aménagées) para preservar los recursos hídricos, la producción de madera, la vida silvestre, los pastizales y el turismo; la conservación de la naturaleza tiene como primer objetivo el mantenimiento de las actividades económicas (aunque pueden designarse sectores particulares en la zona para alcanzar objetivos precisos de conservación)

Existen otras dos categorías de designación internacional que abarcan simultáneamente varias de las ocho nociones descritas anteriormente:

reserva de la biosfera (biosphere reserve, réserve de la biosphère) para conservar, para un uso presente y futuro, la diversidad e integridad de las comunidades bióticas vegetales y animales en el seno de los ecosistemas naturales y salvaguardar la diversidad genética de las especies de las cuales depende su evolución contínua. Se trata de lugares designados internacionalmente y acondicionados para la investigación, la educación y la capacitación

sitio del patrimonio mundial (world heritage site, site du patrimoine mondial) para proteger las realidades naturales que confieren a la zona su importancia universal excepcional

\section{Referencias}

Aird, Paul L. 1979. Report of the biomass strategy consultation: Concluding remarks. Ottawa, Ontario, Canada: Canadian Committee for the Unesco Program on Man and the Biosphere.

Aird, Paul L. 1989. Conservation in a developing nation: The Canadian experience, en Facing North/Facing South, Colloquium on Canadian-American Relations, Western Michigan University, Kalamazoo, Michigan, U.S.A.

Australia, Resource Assessment Commission. 1991. Forest and timber inquiry, draft report, volumen 1. Canberra, Australia: Australian Government Publishing Service.

Baker, Richard J. 1989. Population viability and the Kirtland's 
Warbler, en At the crossroads - extinction or survival. Proceedings, Kirtland's Warbler Symposium, Department of Natural Resources, Lansing, Michigan, U.S.A.

Canada Department of Agriculture. 1976. Glossary of terms in soil science. Ottawa, Ontario, Canada: Research Branch.

Canada, House of Commons. 1981. Still waters: The chilling reality of acid rain. Ottawa, Ontario, Canada: Report of the Sub-committee on Acid Rain of the Standing Committee on Fisheries and Forestry. Canadian Parks Service. 1991. Canadian parks service proposed policy. Ottawa, Ontario, Canada: Environment Canada.

Cody, Martin L. 1986. Diversity, rarity, and conservation in Mediterranean-climate regions, en Soulé, Michael E. (Ed.). Conservation Biology: The Science of Scarcity and Diversity. Sunderland, Massachusetts, U.S.A.: Sinauer Associates, Inc.

Commission of the European Communities. 1983. Glossarium: Alternative energy sources. Bruxelles-Luxembourg, Belgium: Bureau de Terminologie.

Elton, Charles S. 1957. The ecology of invasions by animals and plants. London, England: Methuen and Co.Ltd.

Empire Forestry Association. 1953. British Commonwealth forest terminology: Part 1. London, England: Royal Empire Society.

Gilpin, Michael E., and Michael E. Soulé. 1968. Minimum viable populations: processes of species extinction, en Soulé, Michael E. (Ed.) Conservation Biology: The Science of Scarcity and Diversity. Sunderland, Massachusetts, U.S.A.: Sinauer Associates, Inc.

Hendrickson, Ole. 1993. Science and Sustainable Development Directorate, Forestry Canada, Ottawa, Ontario, Canada: personal communication.

International Council for Research in Agroforestry. 1991. 'ICRAF' in the 'CGIAR': The way ahead. Nairobi, Kenya: International Council for Research in Agroforestry.

International Union for Conservation of Nature and Natural Resources. 1980. World conservation strategy: Living resource conservation for sustainable development. Gland, Switzerland.

Jorgensen, Erik. 1986. Urban forestry in the rearview mirror. Arboreal Journal 10:177-190.

Keystone Center. 1991. Final consensus report of the Keystone policy dialogue on biological diversity on federal lands. Keystone, Colorado, U.S.A.

Lacy, Robert C. 1987. Loss of genetic diversity from managed populations: Interacting effects of drift, mutation, immigration, selection, and population subdivision. Conservation Biology 1(2):143-158. Lacy, R., T. Foose, J. Ballou and J. Eldridge. 1992. Small populations biology and population and habitat viability assessment, en Kirtland's Warbler population and habitat viability assessment briefing book, Captive Breeding Specialist Group, Species Survival Commission, International Union for Conservation of Nature and Natural Resources, Apple Valley, Minnesota, U.S.A.

Mace, Georgina M., and Russell Lande. 1991. Assessing extinction threats: Toward a reevaluation of IUCN threatened species categories. Conservation Biology 5(2):148-157.

Maini, J.S. 1989. Sustainable development and the Canadian forest sector: Discussion paper presented to the Canadian Council of Forestry Ministers. Ottawa, Ontario, Canada: Forestry Canada.

Maini, J.S. 1991. Guiding principles towards a global consensus for the conservation and sustainable development of all types of forests world-wide. Ottawa, Ontario, Canada: Department of Forestry.

Maini, J.S., and A. Carlisle (Eds.). 1974. Conservation in Canada: A conspectus. Ottawa, Ontario, Canada: Canadian Forestry Service, Department of the Environment.

Maini, J.S., and O. Ullsten. 1991. Conservation and sustainable development of forests world-wide: Issues and opportunities. Woods Hole, Massachusetts, U.S.A.: International Workshop, The Conservation and Utilization of World Forests.

McLuhan, Marshall. 1962. The Gutenberg galaxy. Toronto, Ontario, Canada: University of Toronto Press.

McLuhan, Marshall, and Louis Forsdale. 1988. Technology and the human dimension. Antigonish Review No.74-75:21-33.

McNeely, Jeffrey A., Kenton R. Miller, Walter V. Reid, Russell A. Mittermeier and Timothy B. Werner. 1990. Conserving the world's biological diversity. International Union for Conservation of Nature and Natural Resources, Gland, Switzerland: World Resources Institute, Conservation International, World Wildlife Fund-US and the World Bank, Washington, D.C., U.S.A.

Mitchell, Bruce. 1986. The evolution of integrated resource management, en Lang, R. (Ed.) Integrated approaches to resource planning and management. Banff, Alberta, Canada: Banff Centre for Continuing Education.

New Zealand Government. 1991. Resource management act no. 69. Wellington, New Zealand: Government of New Zealand.

Ontario Ministry of Culture and Communications. 1990. A vision of heritage: Heritage goals for Ontario. Toronto, Ontario, Canada: Queen's Printer for Ontario.

Ontario Ministry of Natural Resources and Ministry of Municipal Affairs. 1991. Wetlands: A draft policy for consultation under section 3 of the Planning Act. Toronto, Ontario, Canada.

Ontario Wildlife Working Group. 1991. Looking ahead: A wild life strategy for Ontario. Toronto, Ontario, Canada: Ministry of Natural Resources.

Peel, A.L. 1991. Forest resources commission: The future of our forests. Victoria, British Columbia, Canada: Forest Resources Commission. Pimlott, Douglas H. 1971. Wilderness values in the twentieth century, en Litteljohn, Bruce M., and Douglas H. Pimlott (Eds.) Why Wilderness. New Press, Toronto, Ontario, Canada.

Republic of the Philippines. 1982. Regulations governing the administration, management and disposition of grazing lands, communal grazing lands, and forest lands used for grazing purposes. Diliman, Quezon City, Philippines: Bureau of Forest Development, Ministry of Natural Resources Administrative Order No. 50.

Sargent, Caroline, and M. Lowcock. 1991. Options for the coordination of international action on forest conservation and management, en David Howlett and Caroline Sargent (Eds.), Technical Workshop to Explore Options for Global Forestry Management, Proceedings, Office of the National Environment Board, Bangkok, Thailand.

Society of American Foresters. 1971, 1983. Terminology of forest science technology practice and products, editado por F.C. Ford-Robertson. Washington, D.C., U.S.A.

Society of American Foresters. 1977, 1983. Terminology of forest science technology practice and products, editado por Robert $\mathrm{K}$. Winters. Washington, D.C., U.S.A.

Society of American Foresters. 1989. Recommended changes in silviculture terminology. Manuscrito inedito preparado por Silviculture Instructors's Subgroup, Silviculture Working Group (D2), Bethesda, Maryland, U.S.A.

Tansley, A.G. 1935. The use and abuse of vegetational concepts and terms. Ecology 16(3):284-307.

Tho, Y. P. 1991. Tropical moist forests - facts and issues, en David Howlett and Caroline Sargent (Eds.), Technical Workshop to Explore Options for Global Forestry Management, Proceedings, Office of the National Environment Board, Bangkok, Thailand.

United Nations Environment Programme. 1992. Conference for the adoption of the agreed text of the convention of biological diversity. Nairobi, Kenya: United Nations Environment Programme.

Waring, Richard H., and William H. Schlesinger. 1985. Forest ecosystems; concepts and management. Orlando, Florida, U.S.A.: Academic Press, Inc.

Wilson, Edward O. 1992. The diversity of life. Cambridge, Massachusetts, U.S.A.: Harvard University Press.

World Commission on Environment and Development. 1987. Our common future. Oxford, England: Oxford University Press.

World Conservation Union, United Nations Environment Programme, World Wide Fund for Nature. 1991. Caring for the earth: A strategy for sustainable living. Gland, Switzerland: World Conservation Union. 
World Resources Institute, International Union for Conservation of Nature, United Nations Environmental Programme. 1991. Biodiversity strategy and action plan. Washington, D.C., U.S.A.: World Resources Institute.

World Resources Institute, World Conservation Union, and
United Nations Environment Programme. 1992. Global biodiversity strategy: Guidelines for action to save, study, and use earth's biotic wealth sustainably and equitably. Washington, D.C., U.S.A.: World Resources Institute. 